Research, part of a Special Feature on Do we need new management paradigms to achieve sustainability in tropical forests?

\title{
Use of a Bayesian Belief Network to Predict the Impacts of Commercializing Non-timber Forest Products on Livelihoods
}

\author{
$\underline{\text { Adrian C. Newton }}^{1}$, Elaine Marshall $^{2}$, Kathrin Schreckenberg $^{3}, \underline{\text { Duncan Golicher }}^{4}, \underline{\text { Dirk W. te Velde }}^{3}$, \\ Fabrice Edouard ${ }^{5}$, and Erik Arancibia
}

\begin{abstract}
Commercialization of non-timber forest products (NTFPs) has been widely promoted as a means of sustainably developing tropical forest resources, in a way that promotes forest conservation while supporting rural livelihoods. However, in practice, NTFP commercialization has often failed to deliver the expected benefits. Progress in analyzing the causes of such failure has been hindered by the lack of a suitable framework for the analysis of NTFP case studies, and by the lack of predictive theory. We address these needs by developing a probabilistic model based on a livelihood framework, enabling the impact of NTFP commercialization on livelihoods to be predicted. The framework considers five types of capital asset needed to support livelihoods: natural, human, social, physical, and financial. Commercialization of NTFPs is represented in the model as the conversion of one form of capital asset into another, which is influenced by a variety of socio-economic, environmental, and political factors. Impacts on livelihoods are determined by the availability of the five types of assets following commercialization. The model, implemented as a Bayesian Belief Network, was tested using data from participatory research into 19 NTFP case studies undertaken in Mexico and Bolivia. The model provides a novel tool for diagnosing the causes of success and failure in NTFP commercialization, and can be used to explore the potential impacts of policy options and other interventions on livelihoods. The potential value of this approach for the development of NTFP theory is discussed.
\end{abstract}

Key Words: conservation; NTFP; sustainable development; tropical forest

\section{INTRODUCTION}

In recent years, commercialization of non-timber forest products (NTFPs) has been widely promoted as an appropriate means of developing tropical forest resources (Lawrence 2003, Arnold and Ruiz Pérez 1998, Ruiz Pérez and Arnold 1996). This reflects a growing recognition of the contribution made by many NTFPs to rural livelihoods, both in terms of supporting subsistence and as a means of generating financial income (Arnold and Ruiz Pérez 1998, Belcher 2003). At the same time, because harvesting of NTFPs is generally considered to be less damaging to forest resources than timber extraction, NTFP exploitation is widely believed to be relatively compatible with forest conservation (Arnold and Ruiz Pérez 1998, Belcher 2003, Peters 1996). Thus, commercialization of NTFPs potentially offers a means of achieving both conservation and development goals concurrently (Plotkin and Famolare 1992, Counsell and Rice 1992), by increasing the value of forest resources to local communities (the "conservation-through-use" or "use it or lose it" principle; Dickinson et al. 1996).

Recent reviews suggest that approaches to NTFP commercialization have not, however, been universally successful, and that the scope for improving rural livelihoods through NTFPs is in doubt (Ros-Tonen and Wiersum 2005). For example, Sheil and Wunder (2002) suggest that donor investments for the development of NTFP resources have often been misdirected, and expectations of local income generation potential have frequently been unrealistic. Many NTFPs have been harvested destructively or unsustainably, 
resulting in resource degradation (Peters 1996). In a comprehensive review of NTFP commercialization, Neumann and Hirsch (2000) indicate that sale of NTFPs often tends to provide a low level of income for the poorest section of communities, rather than providing a method of socioeconomic advancement. The NTFP trade may actually perpetuate poverty rather than alleviate it (Neumann and Hirsch 2000). Belcher (2003) notes that the term "NTFP" encompasses a very wide range of forest products and marketing systems, and although some NTFPs appear to be successful in alleviating poverty and contributing to forest conservation, others are harvested very intensively in a manner that results in some stakeholders being excluded from the process.

Given that NTFPs are highly diverse in terms of their ecological and socioeconomic characteristics, there is a need to define which NTFPs have particular potential for development, and under what conditions their use is likely to make a positive contribution to both human livelihoods and forest conservation (Belcher 2003, Lawrence 2003). Such information would help reduce the misdirection of donor investments identified by Sheil and Wunder (2002). However, the high diversity of NTFPs challenges the development of a firm theoretical framework that would enable the potential impacts or outcomes of NTFP commercialization to be predicted. The scientific literature relating to NTFPs, although copious, tends to be characterized by detailed investigations of individual case studies, with relatively little attention given to synthesis, generality, or theory (Neumann and Hirsch 2000). Such developments have been hampered by the lack of an analytical framework that would enable the results from different case studies to be integrated and compared (Arnold and Ruiz Pérez 1996).

Researchers at the Center for International Forestry Research (CIFOR), in Indonesia, have recently developed an analytical approach for classifying NTFP case studies and assessing their development potential, using multivariate statistical approaches. The method aims to simplify the diversity of NTFP case studies by identifying "typologies," or groups of case studies sharing common characteristics. The initial analysis using this method described by Ruiz Pérez and Byron (1999) was based on only nine case studies, limiting the generality of the results (Marshall et al. 2003). However, more recently, the approach has been applied to a much larger number (61) of case studies (Ruiz Pérez et al. 2004). Results were used to group cases into classes according to different household economic strategies, each of which varied in their degree of dependence on NTFPs as a source of income. Such analyses may be of value in highlighting broad groupings of NTFP case studies. However, the existence of discrete strategies remains open to doubt; rather, the data presented by CIFOR illustrate continuous variation among the case studies with respect to the variables considered. In addition, these analyses provide little insight into the relationship between the characteristics of an NTFP and the impact of its commercialization on livelihoods or natural resources. The main limitation of the CIFOR approach is its dependence on correlation; even when relationships are defined, no causation can be inferred.

In this paper, we describe an alternative approach to analyzing the characteristics of different NTFP case studies. Specifically, our objective was to develop a method that would enable the impact of NTFP commercialization on livelihoods to be predicted on the basis of scoring a common set of attributes. In order to make such predictions, some form of modeling approach is required. Progress with developing predictive models of NTFP commercialization has been very limited to date (Arnold and Ruiz Pérez 1998). Most of the models that are available are entirely conceptual in nature (Wilkie and Godoy 1996, Homma 1996). As noted by Arnold and Ruiz Pérez (1998), deterministic models for the management and use of NTFPs are likely to have limited applicability because of the complexity and variability of the situations under which NTFP commercialization takes place. Furthermore, as interdisciplinarity is an essential feature of NTFP research (Neumann and Hirsch 2000), an analytical framework is required that enables different forms of information to be integrated and analyzed, including qualitative and quantitative data drawn from ecological, economic, and social research.

We propose that Bayesian Belief Networks (BBNs) provide an appropriate method for developing predictive models of NTFP commercialization. This method represents information in the form of probabilities, enabling many different sources of data to be integrated and analyzed according to a common framework. The use of a probabilistic, rather than a deterministic, approach to modeling also avoids many of the problems described by Arnold and Ruiz Pérez (1998). Presentation of 
model output in the form of probabilities has the added advantage of being relevant to the needs of decision makers, who in the context of NTFPs require an assessment of risk associated with a particular investment option.

Here, we provide a brief description of BBNs and their application to management of natural resources (Append. 1). We then describe the construction of a BBN to predict the livelihood impacts of NTFP commercialization, according to an analytical framework focusing on the different capital assets required to support livelihoods. The $\mathrm{BBN}$ described here was designed to incorporate information generated by an interdisciplinary research project (CEPFOR) that examined the factors influencing NTFP commercialization in 19 case studies from Mexico and Bolivia (Marshall et al. 2003, 2006). We validate the BBN using field data gathered by this project, and illustrate how the $\mathrm{BBN}$ can be used as a model to predict the impacts of NTFP commercialization on livelihoods and to explore the potential impacts of policy interventions. The contribution of this model to development of a general theory of NTFP management and use is then discussed.

\section{METHODS}

\section{Development of an Analytical Framework}

We employed the Department for International Development (DFID) "livelihoods framework" described by Ashley and Carney (1999) and DFID (1999) as a basis for constructing the BBN (Append. 2 ). This assumes that people require a range of assets (including both material and social resources) in order to achieve positive livelihood outcomes. Five different types of capital asset are considered: natural, physical, human, financial, and social (for definitions, see Append. 2). Following this approach, we consider that communities and individuals involved in NTFP commercialization will require access to each of these five types of assets in order for commercialization to be successful. Furthermore, we propose that the process of NTFP commercialization can be considered as the conversion of one form of capital asset into another. Principally, during NTFP commercialization, natural capital will be converted into financial capital, but during this process the availability of other forms of capital (human, social, and physical) is also likely to change (Fig. 1). The dynamics of the availability of different assets define the potential impact of NTFP commercialization on livelihoods.

\section{Construction of the BBN}

The BBN was constructed, using Hugin Developer 6.3 (http://www.hugin.com/), by creating nodes for each of the five types of capital asset, each of which was given two possible states, "high" and "low," representing the amount of capital available before commercialization. A second set of five nodes was created representing the change in capital assets available resulting from commercialization; these were given five possible states, namely "Large decrease," "Small decrease," "No change," "Small increase," and "Large increase." Each of the nodes representing the availability of capital assets before commercialization was linked to each of the nodes representing change in capital assets resulting from commercialization (Fig. 2).

Results from CEPFOR were used to identify a list of factors that were found to most influence the process of NTFP commercialization. The CEPFOR project investigated 19 NTFP commercialization case studies in Bolivia and Mexico (Marshall et al. 2003, 2006, te Velde et al. 2006) (Table 1), with the explicit aim of identifying the factors influencing success of commercialization. Factors were included on the list if they were identified by the participatory research methods or the statistical analysis of household data collected (see Append. 3, and Marshall et al. 2006). A total of 66 factors were identified, which included the biological characteristics of the products being traded, the socioeconomic characteristics of the producer communities, and the characteristics of the market chains (Append. 3). Each of the factors was then scored for all of the 19 case studies. Scoring was performed by members of the research team familiar with all of the case studies, and was based on all the evidence collected during the CEPFOR research. A complete set of the factors and scores is appended (Append. 7); those factors that most commonly limited commercialization are listed in Table 2. In the $\mathrm{BBN}$, each factor was represented as an individual node, linked to one of the five nodes representing capital asset types available before commercialization. Factors were grouped according 
Fig. 1. Analytical framework for assessing the impact of NTFP commercialization on livelihoods. According to the DFID livelihood framework (see text), five types of capital asset are required to support livelihoods (natural, physical, social, human, financial), which are represented here as a pentagon. Availability of these assets before commercialization is influenced by a range of environmental, political, and socioeconomic factors. The process of NTFP commercialization results in a change in the availability of capital assets, which determines the impact on livelihoods.

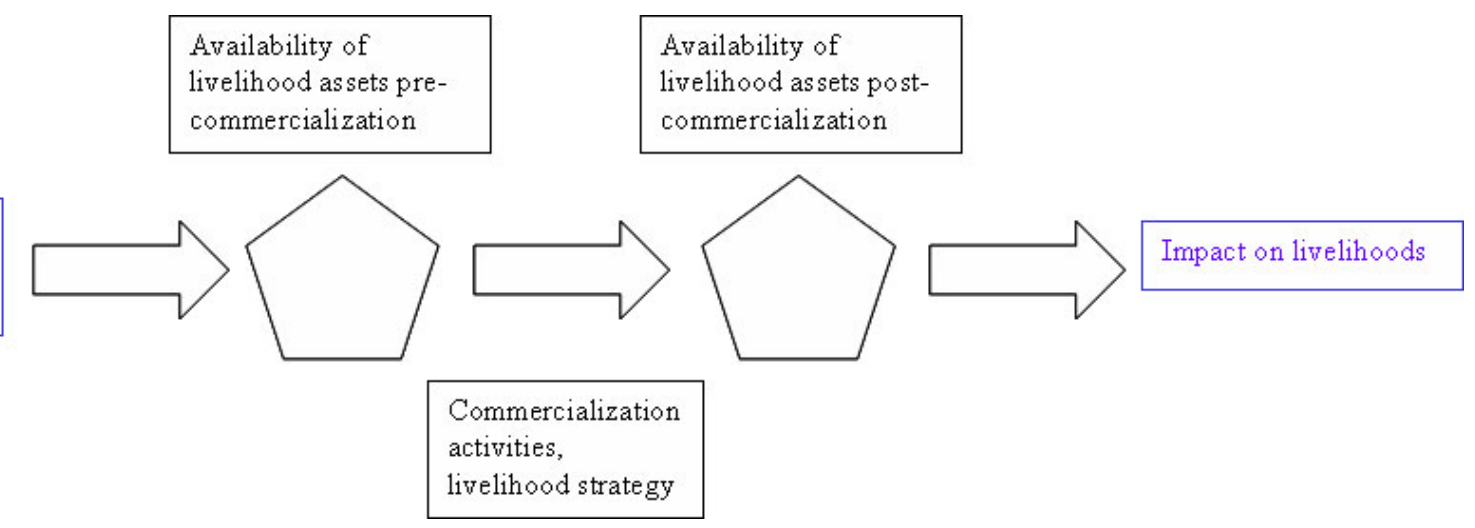

to capital type, such that each factor was linked to a node representing only a single type of capital asset. The assignment of factors to capital types was performed by the project team, on the basis of expert judgement. Definition of the states of each node, and the Conditional Probability Tables (CPTs) associated with each node, are described in Append. 4.

\section{RESULTS}

For the purposes of validating the BBN, two entirely independent data sets were used: one was used as input to the model, and the other was used to test the predictions made. For the former, the scores for each factor generated by the project team on the basis of the research results were used to instantiate the factor nodes for each NTFP case study individually (see Append. 1). Each of the 19 NTFP case studies was saved as a separate BBN case file that could subsequently be reloaded into the network.

A second data set was developed to test the predictions made using the model. This focused on an assessment of the impacts of NTFP commercialization on the communities and households that are actively involved in the commercialization process. A scoring exercise was performed by the staff of partner NGOs associated with the CEPFOR project, who were each familiar with the individual NTFP case studies, having worked directly with the communities involved. This group of experts was invited to assess the impacts of NTFP commercialization on livelihoods using a set of indicators developed by CIFOR (Kusters et al. 2005). These "CIFOR indicators" were developed according to the DFID Livelihood Framework, and organized according to the five types of capital asset described previously. For each of the indicators, the experts were invited to score the impact of NTFP commercialization on the actors in the case study area over the past 10 years using a five-point scale: 2 ("strongly positive"), 1 ("positive"), 0 ("neutral"), -1 ("negative"), and -2 ("strongly negative"). Separate sets of indicators were employed for assessing impacts at both household and community scales. Full details of the indicators used are appended (Append. 8). Technical assistance was provided to each partner by one member of the core research team, to assist in the interpretation of the indicators, and to ensure that the scoring was undertaken in a consistent manner across all case studies.

The impact indicator scores were summed 
Fig. 2. Structure of Bayesian Belief Network $(\mathrm{BBN})$ used to model the impact of NTFP commercialization on livelihoods. Factors are grouped in terms of the type of capital asset that they influence: natural (light green), physical (dark green), social (yellow), human (blue), and financial (red). The availability of each type of asset before commercialization influences availability after commercialization (denoted A in each case). Post-commercialization asset availabilities determine the impacts on livelihoods at both household and community levels, represented by separate nodes in each case.

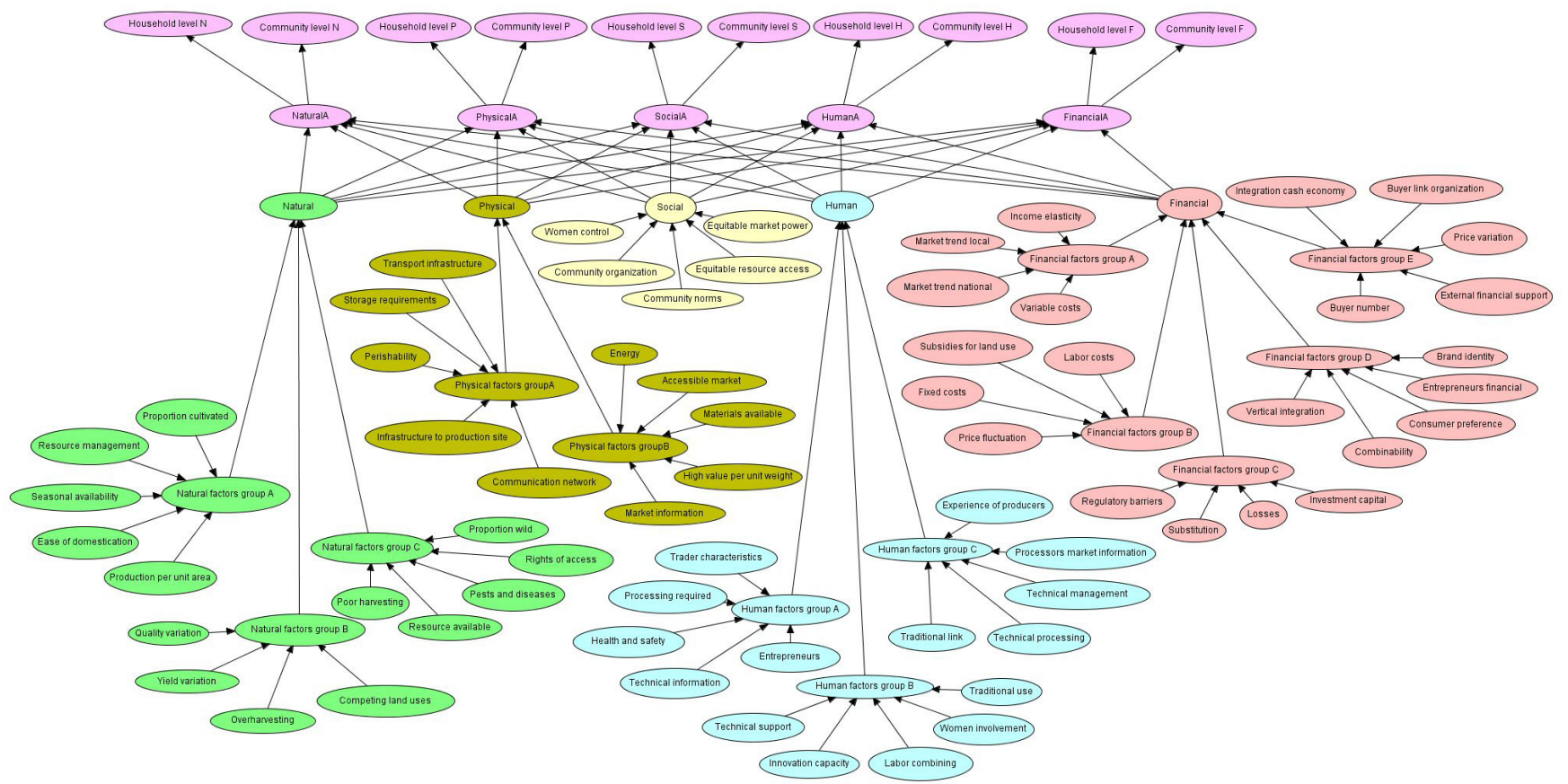

individually for each NTFP case study, pooling data for both household- and community-level indicators. These values were then compared with model predictions for each individual NTFP case study. For this purpose, we used the summed probability values for the "Small increase" and "Large increase" states inferred for the nodes representing the change in assets resulting from commercialization. Data for the different asset types were pooled together for this analysis, but data for individual case studies were kept separate. When analyzed by regression, these two independent sets of values were found to be significantly related $\left(r^{2}=\right.$ $0.66, P<0.001 ;$ Fig. 3$)$. This indicates that the model is able to predict livelihood impact accurately, in terms of the degree of change in assets available, purely from the factor scores used to instantiate the factor nodes, which refer to the biological characteristics of the products being traded, the socioeconomic characteristics of the producer communities, and the characteristics of the market chains. Predicted values were also analyzed as ranks, and again a significant positive relationship was found (Spearman rank correlation, $r=0.80, P$ $<0.001$ ), indicating that the model is also able to predict the relative impacts of different NTFP cases on livelihoods.

As a further test, the frequencies of the different scores provided for the CIFOR livelihood indicators were calculated by pooling household- and community-level responses together, but treating each capital asset type separately. These were then regressed against the proportions of each of the five states inferred for the nodes representing the change in assets resulting from commercialization, including each capital type as a separate set of data points (Fig. 4). For this analysis, predictions were 
Table 1. Details of the case studies included in the CEPFOR project, which formed the basis of the BBN.

\begin{tabular}{|c|c|c|}
\hline Community Names & Species Name & Part used and marketing chain \\
\hline $\begin{array}{l}\text { Carmen del Emero, La Paz, Bolivia } \\
\text { San Silvestre, La Paz, Bolivia }\end{array}$ & $\begin{array}{l}\text { Theobroma cacao } \\
\text { Organic cocoa }\end{array}$ & $\begin{array}{l}\text { Bean extracted from seed pod and traded } \\
\text { Beans processed into cocoa paste }\end{array}$ \\
\hline $\begin{array}{l}\text { Santa Rosa Challana, La Paz, Bolivia } \\
\text { Tomachi, La Paz, Bolivia }\end{array}$ & $\begin{array}{l}\text { Hevea brasiliensis } \\
\text { Natural rubber }\end{array}$ & $\begin{array}{l}\text { Trunk cut for latex and rubber goods } \\
\text { processed } \\
\text { Trunk cut for latex and latex rubber traded }\end{array}$ \\
\hline Pucasucho, La Paz, Bolivia & Clusia and Protium spp. & Trunk cut for resin and incense traded \\
\hline Pucasucho, La Paz, Bolivia & Clusia and Protium spp. & Trunk cut for resin and copal traded \\
\hline $\begin{array}{l}\text { Carmen Surutú, Santa Cruz, Bolivia } \\
\text { Candelaria, Santa Cruz, Bolivia } \\
\text { Potrero San Rafael, Santa Cruz, Bolivia }\end{array}$ & $\begin{array}{l}\text { Carludovica palmata } \\
\text { jipi japa palm }\end{array}$ & $\begin{array}{l}\text { Leaves dried and woven into jipi japa hats } \\
\text { Leaves dried and and woven into jipi japa } \\
\text { tourist crafts } \\
\text { Leaves dried and woven into jipi japa tourist } \\
\text { crafts }\end{array}$ \\
\hline $\begin{array}{l}\text { La Esperanza, Guerrero, Mexico } \\
\text { Topiltepec, Guerrero, Mexico }\end{array}$ & $\begin{array}{l}\text { Brahea dulcis } \\
\text { soyate palm }\end{array}$ & $\begin{array}{l}\text { Leaves boiled, dried, plaited into strips, and } \\
\text { woven into hats, mats, etc. }\end{array}$ \\
\hline La Esperanza, Guerrero, Mexico & $\begin{array}{l}\text { Agave cupreata } \\
\text { Maguey }\end{array}$ & $\begin{array}{l}\text { Heart of the maguey plant fermented to } \\
\text { produce traditional drink mexcal, for trade }\end{array}$ \\
\hline Santa Martha Latuvi, Oaxaca, Mexico & $\begin{array}{l}\text { Tricholoma magnivelare (Matsutake) } \\
\text { wild mushrooms }\end{array}$ & Fruiting body collected and exported fresh \\
\hline $\begin{array}{l}\text { San Antonio Cuajimoloyas, Oaxaco, } \\
\text { Mexico }\end{array}$ & $\begin{array}{l}\text { Amanita caesarea (hongos de huevo) } \\
\text { Cantharellus cibarius (duraznito) } \\
\text { Boletus edulis (porcini) }\end{array}$ & $\begin{array}{l}\text { Fruiting body collected and sold fresh locally, } \\
\text { or dried for regional and national sale }\end{array}$ \\
\hline $\begin{array}{l}\text { Arroyo Blanco, Oaxaco, Mexico } \\
\text { Agua Pescadito, Oaxaco, Mexico }\end{array}$ & $\begin{array}{l}\text { Aechmea magdalenae } \\
\text { Pita }\end{array}$ & $\begin{array}{l}\text { Fiber extracted from the leaves and cleaned } \\
\text { and combed into pita fiber sold for making } \\
\text { thread }\end{array}$ \\
\hline Monte Tinta, Oaxaco, Mexico & $\begin{array}{l}\text { Chamaedorea elegans etc. } \\
\text { camedora palm }\end{array}$ & $\begin{array}{l}\text { Palm fronds collected and traded as bundles } \\
\text { of floral greens }\end{array}$ \\
\hline $\begin{array}{l}\text { Santa Cruz Yagavila, Oaxaco, Mexico } \\
\text { San Miguel Tiltepec, Oaxaco, Mexico }\end{array}$ & Chamaedorea tepejilote & $\begin{array}{l}\text { Inflorescence (clusters of flowers) collected } \\
\text { and sold fresh as food }\end{array}$ \\
\hline
\end{tabular}


Table 2. List of the factors that limited commercialization of more than half of the case studies considered by the CEPFOR project.

Factor

Inequitable exertion of market power along the value chain

Price of the product does not vary in response to changing costs of production

Low development of the brand identity

Lack of an organization that links producers or processors to buyers

NTFP quality is adversely affected by poor harvesting methods

Limited amount of resource available

Lack of a communication network

NTFP value chain does not use the value chain of other products

Lack of provision of financial capital to commercialization (e.g., credit and loans) by entrepreneurs

No external financial support available in the form of credit or loans

Percentage of case studies for which the factor significantly limits commercialization

No traditional link between the producers and the consumers $68 \%$

Producers do not have good access to market information (price, quantity, quality) $68 \%$

There are competing land uses for NTFP production areas $63 \%$

Consumer preference for product quality is not reflected in the price paid to producers $63 \%$

Low level of integration of producers into the cash economy $\quad 63 \%$

Entrepreneurs do not play a positive role in facilitating NTFP commercialization (e.g., $63 \%$ market information and contacts)

$\begin{array}{ll}\text { Yield of the NTFP species varies significantly } & 58 \%\end{array}$

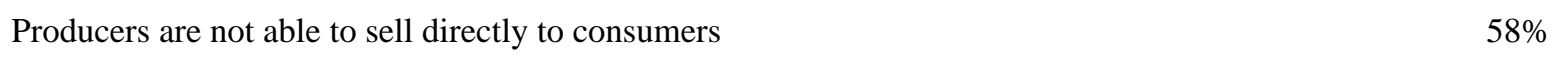

No community norms that facilitate NTFP commercialization $58 \%$

made using the BBN instantiated with probabilities of factor states calculated by pooling together values for all NTFP case studies. Again, the regression was highly significant $\left(r^{2}=0.86, P<0.001\right)$. This indicates that the model is able to capture variation in the availability of assets among different asset types in a way that is consistent with independent measures of livelihood impact.

Explorations of model output, including predicting the potential impact of different policy interventions on livelihoods are described in Append. 5. A decision-support tool based on the BBN has also been made available as a free download (Append. 
Fig. 3. Scatter plot illustrating the relationship between model predictions and livelihood impact scores for 19 individual case studies. Model predictions represent the summed probability values for the "Small increase" and "Large increase" states inferred for the nodes representing the change in assets resulting from commercialization. Data for the different asset types were pooled together for this analysis, but separate model predictions were made for each individual NTFP case study. Livelihood impact scores represent independent measures of the impact of NTFP commercialization on livelihoods assessed using the CIFOR indicators. Indicator scores were summed individually for each NTFP case study, pooling together data for both household- and community-level indicators.

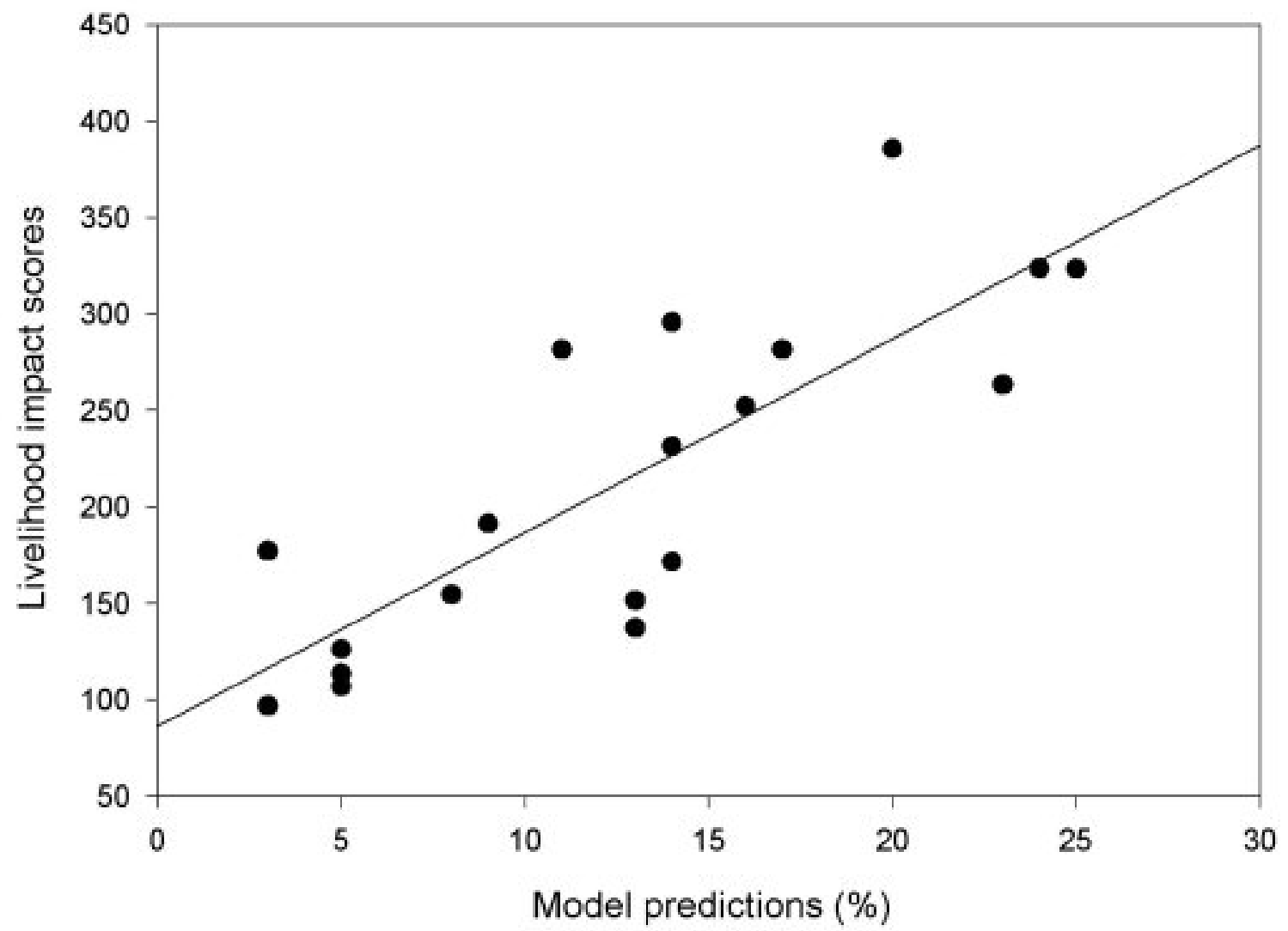

6).

\section{DISCUSSION}

The BBN described here represents the first model of NTFP commercialization to be developed that permits quantitative predictions to be made regarding the potential impacts of NTFP commercialization on livelihoods. The model could potentially be of direct value to decision makers involved in supporting NTFP commercialization initiatives, enabling financial support and other interventions to be focused on those products and socioeconomic circumstances with highest potential for success. In addition, the model could be used to diagnose problems or constraints affecting NTFPs currently undergoing commercialization, and to explore the potential impacts of different policy interventions. The decision-support tool described 
Fig. 4. Scatter plot illustrating the relationship between model predictions and livelihood impact scores, pooling the case studies together. Model predictions represent the probability values (represented as percentages) for the five states of nodes representing the changes in availability of assets required for livelihoods, treating different asset types separately. For these predictions, the network was instantiated with factor values for all NTFP case studies pooled together. Livelihood impact scores represent independent measures of the impact of NTFP commercialization on livelihoods assessed using the CIFOR indicators, pooling household- and community-level responses together, but treating each capital asset type separately.

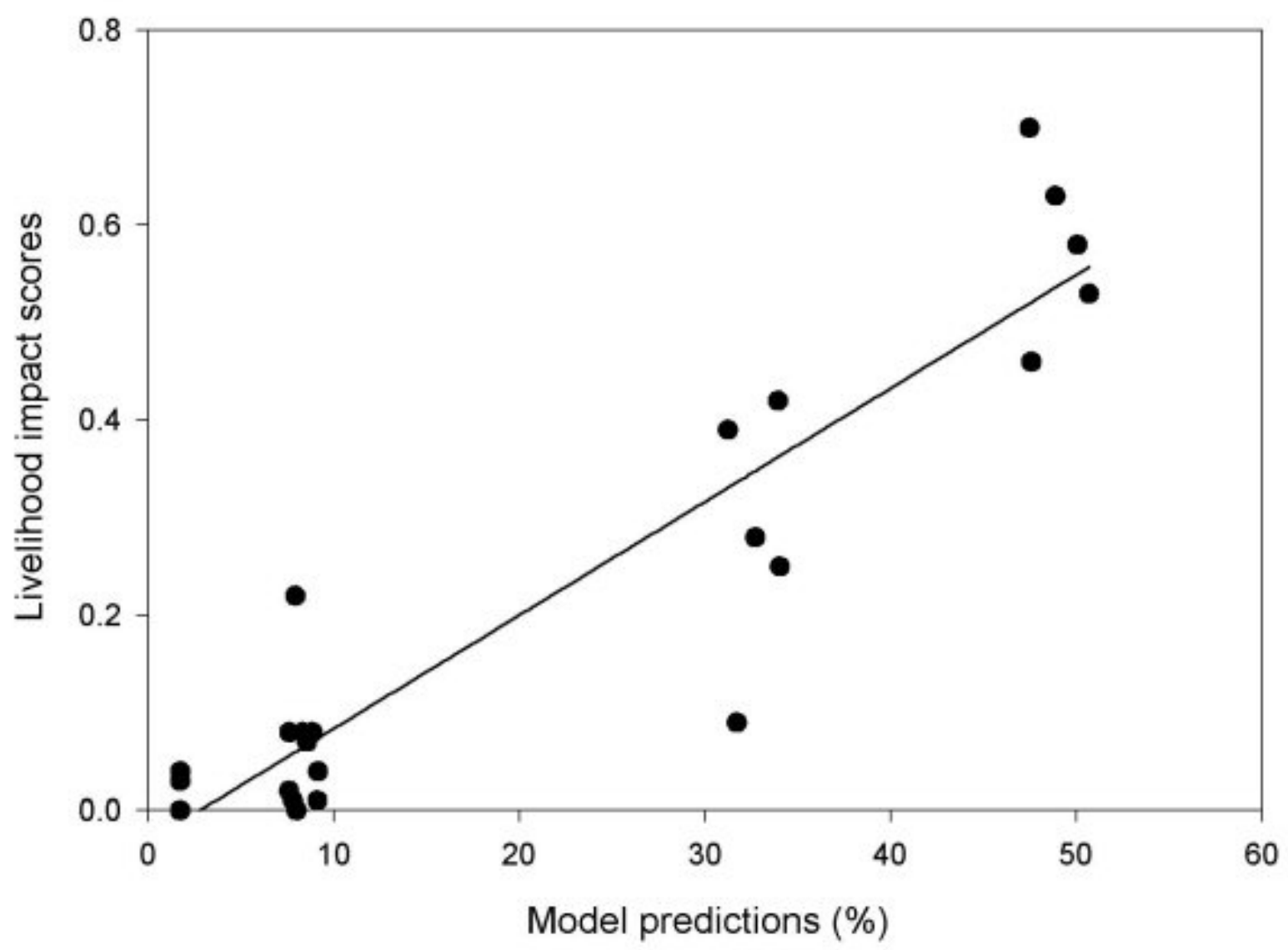

here (Append. 6) based on the model was developed with such practical applications in mind.

However, the value of the model as a decisionsupport tool is clearly limited by the fact that information was based on a sample of only 19 case studies, albeit drawn from more than one country. A key question is the extent to which results obtained here are applicable to other NTFPs and other areas. An important issue for any project taking a case study approach is how widely its findings can be applied; as noted by Belcher (2003), caution is advised in extrapolating results from any single group of NTFPs. However, the aim of the CEPFOR research was not simply to analyze a group of individual case studies in detail, but rather to identify patterns and processes that are generally applicable, and to evaluate under what conditions 
these apply (Marshall et al. 2006). The research findings are likely to be of relevance to many other communities in regions of Latin America that share similar key socioeconomic and geographical characteristics, including poverty level, dependence on forest resources, access to markets, etc. (Marshall et al. 2006). One of the advantages of the BBN approach is that additional information provided by further case studies could readily be incorporated into the model. Conditional probabilities can be updated as additional evidence becomes available through a process of sequential updating, also known as adaptation or sequential learning. The software employed here (Hugin Developer) uses an adaptation algorithm developed by Spiegelhalter and Lauritzen (1990) for this purpose.

The extent to which the list of factors considered here is generally applicable to NTFPs remains to be tested. It is likely that the precise set of factors that influences the process of commercialization will differ between individual NTFP case studies, therefore it might be necessary to include additional factors in the model when extending it to other NTFPs. The analytical framework adopted here enables additional factors to be readily incorporated, simply by identifying the type of capital asset that the factor is deemed to influence and amending the CPTs accordingly. Although the number of factors considered here is large (66), it is substantially fewer than the 114 variables considered by the CIFOR research, which were used to characterize a wide range of attributes of the NTFP case studies considered (Belcher and Ruiz Pérez 2001, Ruiz Pérez et al. 2004).

Differences between the list of factors considered here and the characteristics employed in the CIFOR research may be attributed to the contrasting research approaches adopted. Whereas characteristics were selected by expert judgement in the CIFOR study (Belcher and Ruiz Pérez 2001, Ruiz Pérez et al. 2004), in the current investigation factors were identified through a process of participatory research involving actors participating in NTFP commercialization. Also, in this study, only those factors that had been shown to influence the commercialization process were included. This approach contrasts with the CIFOR research, where an attempt was made to provide a comprehensive characterization of each case study, including a large number of descriptive variables of uncertain value (Belcher and Ruiz Pérez 2001). It is possible that accurate model predictions could be obtained with fewer than the 66 factors considered here, although such a reduction of the factor list would require further evidence to be acquired regarding their relative influence on the commercialization process.

Regardless of the precise selection of factors, we believe that the analytical approach adopted here provides a valuable framework for integrating information from different NTFP case studies, and could potentially be applied to any group of NTFPs. The associations between factors and capital assets can readily be visualized, enabling the relevance of different product characteristics to be rapidly identified and explored. By focusing directly on the different assets required to support livelihoods, the impact of NTFP commercialization on livelihoods can readily be assessed. Adoption of a livelihood framework also facilitates communication of research results to policy makers. Livelihood frameworks and similar asset-based approaches are increasingly being used by a range of aid agencies and development organizations to target development aid and identify appropriate policy interventions (Ashley and Carney 1999, Carney 1998, 2002, DFID 1999). Although the DFID approach was employed here, similar approaches are being used by CARE, the United Nations Development Programme (UNDP), Oxfam, and the FAO (Warner 2000). For example, Siegel (2005) describes use of an asset-based approach to examine policy issues and investment priorities for the World Bank in Latin America and the Caribbean, and Ambrose-Oji (2004) provides details of how sustainable livelihood frameworks have been applied in eight different countries in a range of different production systems. Warner (2000) considers application of the livelihood approach specifically to the forest sector, and highlights its value for defining how forests can contribute to achieving sustainable livelihoods and alleviating poverty. However, livelihood frameworks have never previously been used as anything other than a conceptual tool. For the first time, using a $\mathrm{BBN}$, we have demonstrated here that such frameworks can be operationalized as quantitative analytical models, enabling predictions to be made regarding the potential impacts of different policy interventions on livelihoods. 


\section{Speculation: Implications for Theory}

One of the principal features of previous NTFP research is its theoretical weakness. As noted by Neumann and Hirsch (2000), much NTFP research "appears to be conducted in a theoretical vacuum." Few attempts have been made to explicitly develop or test theories in NTFP research, and those theories that have been developed are generally conceptual or highly qualitative in nature (Neumann and Hirsch 2000, Wilkie and Godoy 1996, Homma 1992, 1996). As a result, many of the research designs employed in NTFP research are based on flawed assumptions, and there is a widespread inability to predict or explain outcomes (Neumann and Hirsch 2000). We support Peters' (1991) assertion that the defining characteristic of theory is its ability to make testable predictions. Given its ability to make such predictions, could the BBN presented here, therefore, be viewed as contribution toward development of general NTFP theory?

Two key questions have been at the center of much NTFP research: (i) does commercialization of NTFPs alleviate poverty? (ii) does NTFP commercialization contribute to forest conservation? The first question arises out of concern that NTFP commercialization strategies may either result in many people only earning a small supplementary income, or a few people earning a significant contribution and disadvantaging others (Neumann and Hirsch 2000). The second question arises out of the belief that commercialization could be combined with forest conservation, and even act as an incentive for it-the so-called "use it or lose it" principle (Dickinson et al. 1996, Freese 1997, Godoy et al. 2000). This hypothesis is based on three key assumptions: (i) forests have a greater long-term economic value if they are left standing, rather than being converted to some other land use; (ii) local communities will be more likely to manage forest resources sustainably if they gain direct economic benefits from harvesting forest products; (iii) poverty in rural tropical areas is both a cause and a result of forest loss and degradation (Neumann and Hirsch 2000). Resource depletion may prompt different responses, including moving to different harvesting areas or initiating new management regimes. Homma's (1992, 1996) well-known conceptual model proposes that increasing commercialization will inevitably result in overexploitation of wild resources, leading to two possible scenarios: domestication or synthesis/ substitution of the product.
Could the model described here be of value in addressing such questions? The $\mathrm{BBN}$ is designed to predict the impact of different interventions on the assets required to support livelihoods. The approach is also designed to enable generalizations to be made on the basis of information from individual case studies. The impact of policy interventions on components of poverty alleviation such as income generation could be examined, for example by assessing changes in the availability of financial capital to actors involved in commercialization. Similarly, the impact of commercialization on forest resources could be evaluated by assessing changes in the availability of natural capital. However, in order to address these questions fully, information is needed on how people make decisions regarding the trade-offs between different capital assets, such as natural and financial capital, in relation to their immediate and long-term needs. Furthermore, it should be remembered that NTFPs offer just one among several alternative livelihood strategies that may be available. A comprehensive theory would, therefore, incorporate the decision-making processes of the actors involved in NTFP commercialization regarding which livelihood strategies to adopt under different circumstances. Although trade-offs between different assets could be explored using the model as described here, incorporation of decisionmaking processes would require extending the $\mathrm{BBN}$ to include factors that influence selection of alternative livelihood strategies. Alternatively, other approaches such as agent-based models might be of value in this context (Lambin et al. 2003). Our belief is that understanding how the availability of different livelihood options affects people's decisions about NTFP commercialization currently lies at the frontier of NTFP research.

Responses to this article can be read online at:

http://www.ecologyandsociety.org/voll 1/iss2/art24/responses/

\section{Acknowledgments:}

The authors thank the communities and traders who participated in this work. Finbarr O'Sullivan (URL: http://mapinformatics.com/) designed the Java interface that is incorporated in the CEPFOR Decision Support Tool. This publication is an output from a research project funded by the U.K. Department for International Development (DFID) for the benefit of developing countries. The views 
expressed are not necessarily those of DFID. Project R7925 Forestry Research Programme.

\section{LITERATURE CITED}

Ambrose-Oji, B. 2004. Livelihoods synthesis study: key determinants of poor people's livelihood strategies and natural resources-related management opportunities. Department for International Development (DFID) Natural Resources Systems Programme, Hemel Hempstead, UK.

Arnold, J. E. M., and M. Ruiz Pérez. 1996. Framing the issues relating to non-timber forest products research. Pages 1-18 in M. Ruiz Pérez and J. E. M. Arnold, editors. Current issues in nontimber forest products research. Center for International Forestry Research (CIFOR), Bogor, Indonesia.

Arnold, J. E. M., and M. Ruiz Pérez. 1998. The role of non-timber forest products in conservation and development, Pages 17-42, in E. Wollenberg and A. Ingles, editors. Incomes from the forest: methods for the development and conservation of forest products for local communities. Center for International Forestry Research (CIFOR), Bogor, Indonesia.

Ashley, C., and D. Carney. 1999. Sustainable livelihoods: lessons from early experience. Department for International Development (DFID) Issues series, London, UK.

Belcher, B. M. 2003. What isn't an NTFP? International Forestry Review 5(2):161-168.

Belcher, B., and M. Ruiz Pérez. 2001. An international comparison of cases of forest product development: overview, description and data requirements. CIFOR Working Paper Number 23. Center for International Forestry Research (CIFOR), Bogor, Indonesia. [online] URL: http://w ww.cifor.cgiar.org/publications/ntfpsite/docs/details/ detail-wp23.htm.

Bromley, J., N. A. Jackson, O. J. Clymer, A. M. Giacomello, and F. V. Jensen. 2005. The use of Hugin to develop Bayesian networks as an aid to integrated water resource planning. Environmental Modelling and Software 20(2):231-242.
Burgman, M. 2005. Risks and decisions for conservation and environmental management. Cambridge University Press, Cambridge, UK.

Cain, J. D., C. H. Batchelor, and D. K. N. Waughray. 1999. Belief networks: a framework for the participatory development of natural resource management strategies. Environment, Development and Sustainability 1:123-133.

Carney, D., editor. 1998. Sustainable rural livelihoods: what contribution can we make? Department for International Development (DFID), London, UK. [online] URL: http://www.livelihoods. org.

Carney, D. 2002. Sustainable livelihoods approaches: progress and possibilities for change. Department for International Development (DFID), London, UK. [online] URL: http://www.livelihoods. org.

Counsell, S., and T. Rice, editors. 1992. The rainforest harvest: sustainable strategies for saving the tropical forests? Friends of the Earth Trust Ltd., London, UK.

Crome, F. H. J., M. R. Thomas, and L. A. Moore. 1996. A novel Bayesian approach to assessing impacts of rain forest logging. Ecological Applications 6:1104-1123.

Department for International Development (DFID). 1999. Sustainable livelihoods guidance sheets. DFID, London, UK. [online] URL: http://w ww.livelihoods.org.

Dickinson M. B., J. C. Dickinson, and F. E. Putz. 1996. Natural forest management as a conservation tool in the tropics: divergent views on possibilities and alternatives. Commonwealth Forestry Review 75(4):309-315.

Ellison, A. M. 1996. An introduction to Bayesian inference for ecological research and environmental decision-making. Ecological Applications 6:10361046.

Freese, C. H. 1997. The "use it or lose it' debate: issues of a conservation paradox. Pages 1-48 in C. $\mathrm{H}$. Freese, editor. Harvesting wild species. Implications for biodiversity. John Hopkins University Press, Baltimore, Maryland, USA. 
Gertner, G. Z., and H. Zhu. 1996. Bayesian estimation in forest surveys when samples or prior information are fuzzy. Fuzzy Sets and Systems 77:277-290.

Ghazoul, J., and M. McAllister. 2003. Communicating complexity and uncertainty in decision making contexts: Bayesian approaches to forest research. International Forestry Review 5 (1):9-19.

Godoy, R., D. Wilkie, H. Overman, A. Cubas, G. Cubas, J. Demmer, K. McSweeney, and N. Brokaw. 2000. Valuation of consumption and sale of forest goods from a Central American rain forest. Nature 406:62-63.

Haas, T. C. 1991. A Bayesian belief network advisory system for aspen regeneration. Forest Science 37:627-654.

Heckerman, D. 1996. A tutorial on learning with Bayesian networks technical report MSRTR-95-06. Microsoft Research Advanced Technology division. [online] URL: http://research.microsoft.com/ research/pubs/view.aspx?msr tr id=MSP-TR-95-06

Homma, A. K. O. 1992. The dynamics of extraction in Amazonia: a historical perspective. Pages 23-32 in D. C. Nepstad and S. Schwartzman, editors. Nontimber forest products from tropical forests: evaluation of a conservation and development strategy. New York Botanical Garden, New York, New York, USA.

Homma, A. K. O. 1996. Modernisation and technological dualism in the extractive economy in Amazonia. Pages 59-82 in M. Ruiz Pérez and J. E. M. Arnold, editors. Current issues in non-timber forest products research. Center for International Forestry Research (CIFOR), Bogor, Indonesia.

Jensen, F. V. 2001. Bayesian networks and decision graphs. Springer, New York, New York, USA.

Kusters, K., B. Belcher, M. Ruiz Pérez, and R. Achdiawan. 2005. A method to assess the outcomes of forest product trade on livelihoods and the environment. CIFOR working paper No. 33. Center for International Forestry Research (CIFOR), Bogor, Indonesia.
Lagos, N. A., and J. C. Castilla. 1997. Bayesian statistical inference in ecology: an example of its use in a Chilean marine preserve. Revista Chilena de Historia Natural 70:565-575.

Lambin, E. F., Gesit, H. J., and Lepers, E. 2003. Dynamics of land-use and land-cover change in tropical regions. Annual Review of Environment and Resources 28:205-241.

Lauritzen S. L., and D. J. Spiegelhalter. 1988. Local computations with probabilities on graphical structures and their application to expert systems. Journal of the Royal Statistical Society B 50:157224.

Lawrence, A. 2003. No forest without timber? International Forestry Review 5(2):87-96.

Marcot, B. G., R. S. Holthausen, M. G. Raphael, M. Rowland, and M. Wisdom. 2001. Using Bayesian belief networks to evaluate fish and wildlife population viability under land management alternatives from an environmental impact statement. Forest Ecology and Management 153 (1-3):29-42.

Marshall, E., A. C. Newton, and K. Schreckenberg. 2003. Commercialising nontimber forest products: first steps in analysing the factors influencing success. International Forestry Review 5(2): 128-137.

Marshall E., K. Schreckenberg, and A. C. Newton, editors. 2006. Commercialization of nontimber forest products. Factors influencing success. Lessons learned from Mexico and Bolivia and policy implications for decision-makers. UNEP World Conservation Monitoring Centre, Cambridge, UK.

Neil, M., N. Fenton, and L. Nielson. 2000. Building large-scale Bayesian networks. The Knowledge Engineering Review 15(3):257-284.

Neumann, R. P., and E. Hirsch. 2000. Commercialisation of non-timber forest products: review and analysis of research. Center for International Forestry Research(CIFOR), Bogor, Indonesia. 176 p.

Pearl, J. 1986. Fusion, propagation and structuring in belief networks. Artificial Intelligence 29:241288. 
Pearl, J. 1988. Probabilistic reasoning in intelligent systems: networks of plausible inference. Morgan Kaufmann Publishers, Inc., San Mateo, California, USA.

Pearl, J. 1995. Causal diagrams for empirical research. Biometrika 82(4):669-688.

Peters, R. H. 1991. A critique for ecology. Cambridge University Press, Cambridge, UK.

Peters, C. M. 1996. Observations on the sustainable exploitation of non-timber tropical forest products. Pages 19-39 in D. C. Nepstad and S. Schwartzman, editors. Non-timber forest products from tropical forests: evaluation of a conservation and development strategy. New York Botanical Garden, New York, New York, USA.

Plotkin, M., and L. Famolare, editors. 1992. Sustainable harvest and marketing of rain forest products. Island Press, Washington, D.C., USA.

Reckhow, K. H. 2003. Bayesian approaches in ecological analysis and modeling. Pages 168-183 in C. D. Canham, J. J. Cole, and W. K. Lauenroth, editors. Models in ecosystem science. Princeton University Press, Princeton, New Jersey, USA.

Rieman, B., J. T. Peterson, J. Clayton, P. Howell, R. Thurow, W. Thompson, and D. Lee. 2001. Evaluation of potential effects of federal land management alternatives on trends of salmonids and their habitats in the interior Columbia River Basin. Forest Ecology and Management 153:43-62.

Ros-Tonen, M. A. F., and K. F. Wiersum. 2005. The scope for improving rural livelihoods through non-timber forest products: an evolving research agenda. Forests, Trees and Livelihoods 15:129-148.

Ruiz Pérez, M., and J. E. M. Arnold, editors. 1996. Current issues in non-timber forest product research. ODA/CIFOR, Center for International Forestry Research, Bogor, Indonesia.

Ruiz Pérez, M., and N. Byron. 1999. A methodology to analyze divergent case studies of non-timber forest products and their development potential. Forest Science 45(1):1-14.

Ruiz Pérez, M., B. Belcher, R. Achdiawan, M. Alexiades, C. Aubertin, J. Caballero, B.
Campbell, C. Clement, T. Cunningham, A. Fantini, H. de Foresta, C. García Fernández, K. H. Gautam, P. Hersch Martínez, W. de Jong, K. Kusters, M. G. Kutty, C. López, M. Fu, M. A. Martínez Alfaro, T. R. Nair, O. Ndoye, R. Ocampo, N. Rai, M. Ricker, K. Schreckenberg, S. Shackleton, P. Shanley, T. Sunderland, and Y. Youn. 2004. Markets drive the specialization strategies of forest peoples. Ecology and Society 9 (2):4. [online] URL: http://www.ecologyandsociety. org/vol9/iss2/art4.

Sheil, D., and S. Wunder. 2002. The value of tropical forest to local communities: complications, caveats, and cautions. Conservation Ecology 6(2): 9. [online] URL: http://www.consecol.org/vol6/iss2/ art9.

Spiegelhalter, D. J., and S. L. Lauritzen. 1990. Sequential updating of conditional probabilities on directed graphical structures. Networks 20 (56):579-605.

Spiegelhalter, D. J., A. P. Dawid, S. L. Lauritzen, and R. G. Cowell.1993. Bayesian analysis in expert systems. Statistical Science 8(3):219-283.

Siegel, P. B. 2005. Using an asset-based approach to identify drivers of sustainable rural growth and poverty reduction in Central America: a conceptual framework. Policy, Research working paper series; no. WPS 3475. World Bank Group, Washington, D. C., USA. [Online] URL: http://wdsbeta.worldbank. org/.

te Velde D. W., J. Rushton, K. Schreckenberg, E. Arancibia, F. Edouard, E. Marshall, and A. C. Newton. 2006. Entrepreneurship in value chains of non-timber forest products. Forest Policy and Economics 8(7): 725-741.

Varis, O. 1997. Bayesian decision analysis for environmental and resource management. Environmental Modelling and Software 12:177-185.

Warner, K. 2000. Forestry and sustainable livelihoods. Unasylva 51(202):3-12.

Wilkie, D. S., and R. A. Godoy. 1996. Trade, indigenous rain forest economies and biological diversity. Model predictions and directions for research. Pages 83-102 in M. Ruiz Pérez and J. E. M. Arnold, editors. Current issues in non-timber forest products research. Center for International 
Forestry Research (CIFOR), Bogor, Indonesia. 
APPENDIX 1. Bayesian Belief Networks (BBN) in natural resource management.

A BBN may be defined most simply as a graphical model that incorporates probabilistic relationships among variables of interest (Heckerman 1996). The term "graphical model" is used because the BBN can be represented in the form of an influence diagram. An influence diagram can be used to provide a visual representation of the components and dependencies of a system. Different shapes (such as ellipses and rectangles) can be used to represent variables, data and parameters, which are connected by arrows to indicate causal relationships and dependencies (Burgman 2005). In the case of a BBN, the ellipses representing variables are referred to as nodes. The arrows are referred to formally as directed links (Jensen 2001). A probability function is attached to each node, and probabilities are combined in the model using Bayes' theorem. A BBN therefore provides both a tool for reasoning under uncertainty and a statistical model of the domain of interest (Jensen 2001).

Bayesian networks evolved in the early 1990s drawing on a deep body of theory developed for graphical models in general, due in large part to the seminal work of Pearl $(1986,1988,1995)$, who established their position at the interface between statistics, applied artificial intelligence and expert system development. BBNs may be used for both predictive modelling of domain knowledge and as thought tools for structuring and analysing the results of experience in a domain. The growing interest in applying belief networks to resource management problems may be linked to the increased acceptation of Bayesian statistical approaches in general. Typically Bayesian statistics are used to find parameter values when the stochastic component of a model is represented by one or more continuous probability density functions. The directed acyclical graphs used to represent these models can follow the same formalisms as BBNs.

Bayesian analytical techniques began to be considered seriously by ecologists and resource managers largely as a result of a special addition of Ecological Applications published in 1996 (e.g. Ellison 1996). Crome et al. (1996) provided an example that showed how Bayesian methods may be particularly useful in the context of tropical forest management, for modeling the inevitably subjective uncertainties involved when forest systems are disturbed. Gertner and Zhu (1996) reached a similar conclusion in a rather narrower context. The key advantages of Bayesian methods, including BBNs, for both forestry and conservation applications concern their ability to ensure that subjectivity is explicit and transparent rather than implicit in the choices made regarding which elements in the data are presented and emphasized (Ghazoul and McAllister 2003). Lagos and Castilla (1997) also stressed this advantage when they applied Bayesian methods to the problem of managing a marine reserve.

From their inception it was clear that Bayesian networks had a great potential for building working expert systems (Lauritzen and Spiegelhalter 1988). Some successful early applications were in the field of medical diagnosis (Spiegelhalter et al. 1993). The application of such methods to resource management problems were first explored rather later (Varis 1997). One of the earliest published examples was by Haas (1991), who applied the method to a very narrow domain, the problem of predicting the density of suckers produced by rocky mountain aspen in response to a range of management options. The study stressed the flexibility of BBNs as a knowledge representation system which was contrasted with more rigid rule-based expert systems. Although the work did not reach the stage of evaluating model predictions against an independent data set, the conclusion was reached that BBNs produce results consistent with expert judgment even when precise parameter estimation is challenging.

Cain et al. (1999) have demonstrated how belief networks can be extended into the social domain of resource management. The authors stressed the importance of ensuring that rural stakeholders are involved in the identification of key variables. They also showed how BBNs can use locally derived data and experiences in a flexible and adaptive manner. This work did not however clarify methods for parameterizing BBNs in the context of participatory rural appraisal. Other recent applications of BBNs in resource management include those developed by Rieman et al. (2001) and Marcot et al. (2001) who 
developed BBNs for aquatic and terrestrial vertebrate species found on federal lands within the interior Columbia River basin in the United States, and Bromley et al. (2005) who explored their application to integrated water resource planning. Other references to recent research on this theme are provided by Reckhow (2003). However, we are not aware of any previous attempt to apply BBNs to the management and use of NTFPs in tropical forests. Although Ghazoul and McAllister (2003) provide a detailed account of the value of Bayesian approaches to forest research, particularly with respect to supporting adaptive management and decision-making, little explicit consideration is given to BBNs.

One of our motives for using BBNs was a desire to explicitly model belief. Under the Bayesian paradigm, evidence that is consistent with a given hypothesis (e.g. success of commercialisation) has a high likelihood. When Bayes' theorem is used, this results in a strengthening in the belief in the hypothesis. We stress that under this interpretation "probability of success" does not refer to a prognosis of any future state. Rather it represents a strong belief based on accumulated evidence that NTFP commercialisation is successful.

The practical development of a BBN begins with construction of an influence diagram, which can be based on expert knowledge or belief about the domain of interest. The creation of an influence diagram can itself be a useful way of eliciting information from experts and structuring the information available (Burgman 2005). As in the current research, a number of different model structures may be explored, with the aim of identifying the structure that best captures the logical relationships between the variables being considered. One the structure has been defined, the main challenge is to complete the Conditional Probability Tables (CPTs) that are associated with each node. These define the probabilistic relationships between the nodes connected by directed links. Further details of how the BBN was constructed in the present study are given in App. 5.

A BBN can be explored by changing the states of the nodes (or variables) incorporated within the model. When the state of a variable is known, it is said to be instantiated (Jensen 2001). Once a node has been instantiated, then this will influence the probabilities associated with the states of other nodes to which it is linked, according to the values in the CPTs. In the current example, the BBN was instantiated by entering the factor scores obtained for each case study individually. 
APPENDIX 2. Development of an analytical framework.

Progress in developing models for NTFPs has been hindered by the lack of an analytical framework that would enable information from diverse NTFPs to be integrated and analysed (Arnold and Ruiz Pérez 1998). As the objective here was to predict the impact of NTFP commercialization on livelihoods, we adopted a 'livelihoods framework' as a basis for constructing the BBN. Livelihood frameworks are designed to assist with analysing and understanding the livelihoods of the poor and to assess the effectiveness of current efforts aimed at reducing poverty; increasingly such frameworks are being used in development planning and policy (Carney 2002). Here, we employed the DFID Livelihoods framework described by Ashley and Carney (1999) and DFID (1999). This framework is based on the concept that people require a range of assets (including both material and social resources) in order to achieve positive livelihood outcomes. Five different types of asset are considered (DFID 1999):

1. Natural capital, which includes the natural resource stocks from which products and services useful for livelihoods are derived.

2. Physical capital, which comprises the basic infrastructure and producer goods needed to support livelihoods (e.g. shelter and buildings; tools and equipment used for farming or forest management; transportation, energy and communications; etc.).

3. Human capital, which includes the skills, knowledge, ability to work and health that people need to pursue different livelihood strategies and achieve their objectives.

4. Financial capital, which includes the financial resources that people use to achieve their livelihood objectives, including savings in various forms, access to credit, earnings and remittances.

5. Social capital, which refers to the social resources that people draw upon to help meet their livelihood objectives, including networks and connections between people, and the rules, norms and sanctions associated with different institutions.

Following the DFID approach, we consider that communities and individuals involved in NTFP commercialization as part of a livelihood strategy will require access to each of these five types of asset in order for commercialization to be successful. Furthermore, we propose that the process of NTFP commercialization can be considered as the conversion of one form of capital asset into another. Principally, during NTFP commercialization natural capital will be converted into financial capital, but during this process the availability of other forms of capital (human, social and physical) is also likely to change. Therefore, according to this approach, the process of NFTP commercialization can be conceptualized as a change in the availability of the five different types of capital asset. The extent and pattern of this change will be influenced by the initial availability of each of these asset types. Furthermore, the overall impact of NTFP commercialization on livelihoods can be considered as a function of the change in the availability of these assets (Figure 1).

The extent to which the availability of different types of asset varies as a result of NTFP commercialization will depend on a wide range of social, economic and environmental factors, as well as the cultural and political context under which the commercialization takes place. These factors include the characteristics of the product to be commercialized, and also the characteristics of the value chain (or market chain). The list of factors that could potentially influence the success of NTFP commercialization is not only large, but also varies between products and between the socio-economic circumstances under which commercialization takes place.

It is this complexity that has hindered progress in developing models for NTFP use and management to date. However, according to the analytical framework described here, such factors can be grouped 
according to the type of capital asset that they primarily affect. The framework therefore provides a basis for organizing information about a diverse array of variables that may have an influence on the process of NTFP commercialization. Furthermore, this framework focuses attention on the causal or probabilistic relationships between such factors and the pattern of change in availability of different asset types, providing a link between these factors and the impact on livelihoods.

The selection of factors to be incorporated in the model should be informed by the results of research, which ideally should be participatory, to ensure that the views of the actors involved in NTFP commercialization are adequately represented. Here we used the results of the CEPFOR research project to build a BBN according to the analytical framework described above. 


\section{APPENDIX 3. The CEPFOR project.}

CEPFOR is an interdisciplinary research project that has investigated 19 NTFP commercialization case studies in Bolivia and Mexico (Marshall et al. 2003, 2006, te Velde et al. 2006), with the explicit aim of identifying the factors influencing success of commercialization. For each product a structured 'market' report was written based on a combination of secondary data and key informant interviews at various points along the market chain. These reports described the main market chains for the product, beginning in the study communities and tracking information as far downstream to the final consumer as possible. For each of the case studies a structured 'community' report was also written, based on secondary information and data collected by partner NGOs using participatory techniques (such as timelines, resource mapping, wealth-ranking, Venn diagrams) and key informant interviews.

The data collected covered a wide range of topics necessary for the understanding of current patterns of resource use and management, with a focus on the collection, cultivation, processing and marketing of the case study NTFP. In addition, a formal household questionnaire was used to collect data about the household, its use of the NTFP including any costs and benefits incurred, and the interviewees' perceptions of the household's success and the contribution of NTFPs to their livelihood strategy. In 2002/3 the questionnaire was applied to a total of 289 households divided between the case study communities. Households were sampled using a stratified approach on the basis of participatory wealthranking. A further 117 households not involved in NTFP activities were also interviewed to provide controls. In addition 46 national traders were interviewed using a slightly modified version of the questionnaire. Data analysis included comparative text analysis of the community reports, statistical analysis (principally correlation and regression analysis) of the household data, and construction of value chains (on the basis of the household data and the market reports) for each case study. Full results are presented by Marshall et al. (2006).

These research results were used to identify a list of factors that were found to most influence the process of NTFP commercialization in the case studies examined. For each factor, supporting evidence was available indicating that the factor has a significant influence on the commercialization on one or more of the NTFP case studies examined. Factors were included on the list if they were identified by the participatory research methods (i.e. mentioned by respondents in the informant interviews or questionnaires), or the statistical analysis of household data. These factors include the characteristics of the product to be commercialized, but also include the socio-economic characteristics of the communities involved, and the characteristics of the value chain.

A total of 66 factors were included on the list (App. 4). Each of the factors was then scored for all of the 19 case studies. Scoring was performed by members of the research team familiar with all of the case studies, and was based on all the information sources generated during the research. The nature of the scores differed between the factors, but in the majority of cases a simple Boolean response was employed, indicating whether or not there was any evidence that a given factor had influenced the process of commercialization in that particular case. A complete set of the scores is appended (App. 4).

Those factors that limited NTFP commercialization in more than 60 per cent of the case studies are listed below, grouped into three categories. The percentage value given in brackets represents the proportion of communities in which a particular factor limited success by reducing the availability of physical, natural, financial, human and social capital assets required for commercialization.

\section{(A) Structure and function of the value chain}

- Inequitable exertion of market power along the value chain (79)

- $\quad$ Price of the product does not vary in response to changing costs of production (74) 
- Low development of the brand identity (74)

- Lack of an organization that links producers or processors to buyers (74)

- $\quad$ NTFP value chain does not use the value chain of other products (68)

- Lack of provision of financial capital to commercialization (e.g. credit and loans) by entrepreneurs (68)

- No traditional link between the producers and the consumers (68)

- Producers do not have good access to market information (price, quantity, quality) (68)

- Consumer preference for product quality is not reflected in the price paid to producers (63)

- Lack of entrepreneurs facilitating NTFP commercialization (e.g. through market information and contacts) (63)

\section{(B) Community social and economic context}

- $\quad$ Lack of a communication network (68)

- No external financial support available in the form of credit or loans (68)

- Low level of integration of producers into the cash economy (63)

\section{(C) Natural resource issues}

- $\quad$ NTFP quality is adversely affected by poor harvesting methods (74)

- $\quad$ Limited amount of resource available (68)

- $\quad$ Competing land uses for NTFP production areas (63)

Some general points emerging from these results are presented below (see Marshall et al. 2006 for a more detailed discussion):

- The most widespread constraint to commercialisation among the case studies was inequitable exertion of market power along the value chain, reported in $79 \%$ of cases. Other widespread factors, affecting $74 \%$ of cases, were that the price of the product does not vary in response to changing costs of production, low development of the brand identity, lack of an organization that links producers or processors to buyers, and NTFP quality being adversely affected by poor harvesting methods.

- The grouping of the factors highlights the fact that value chain issues were particularly widespread for households and communities, with factors relating to natural-resource issues or the social and economic context of communities being of importance to a relatively low proportion of case studies.

- Households, communities and traders showed a high degree of innovation in overcoming factors constraining successful NTFP commercialization. Some factors, however, such as integration of producers into the cash economy, were outside their control. Understanding the degree to which different actors in the NTFP value chain are able to influence different factors is important for 
determining appropriate policy interventions.

- The linked nature of some of the factors - e.g. lack of producer/processor organization can result in inequitable exertion of market power by other actors in the value chain - suggests the need to recognize that policy interventions designed to address one factor may have knock-on effects on other factors.

- Not all factors are equally amenable to policy- or project-level interventions, and such interventions differ in terms of their impacts. The CEPFOR decision support tool, based on the $\mathrm{BBN}$, allows users to explore the potential impacts of different policy scenarios on households and communities, by amending the values of factor scores (App. 7). 
Appendix 4. See attached spreadsheet - factor scores

Please click here to download file 'appendix4.xls'. 


\section{APPENDIX 5. Construction of the BBN.}

The BBN was constructed using Hugin Developer 6.3, a commercial software package developed and distributed by Hugin Expert A/S, Aalborg, Denmark (http://www.hugin.com/). The BBN was constructed by representing variables as nodes connected by directed links (see Appendix 1), which are indications of conditional dependence. A link from node A (parent node) to node B (child node) indicates that $\mathrm{A}$ and $\mathrm{B}$ are functionally related, or that $\mathrm{A}$ and $\mathrm{B}$ are statistically correlated. Each child node (i.e. a node linked to one or more parents) contains a conditional probability table (CPT). The CPT gives the conditional probability for the node being in a specific state given the configuration of the states of its parent nodes. When networks are compiled, Bayes' theorem is applied according to the values in the CPT, so that changes in the probability distribution for the states at node A are reflected in changes in the probability distribution for the states at node B.

Nodes were created for each of the five types of capital asset and given two possible states, 'high' and 'low', representing the amount of capital available prior to commercialization. A second set of five nodes was created representing the change in capital assets available resulting from commercialization; these were given five possible states, namely 'Large decrease', 'Small decrease', 'No change', 'Small increase', and 'Large increase'. According to the framework described above, each of the nodes representing the availability of capital assets prior to commercialization was linked to each of the nodes representing change in capital assets resulting from commercialization.

Each of the factors that influences the NTFP commercialisation process (see Appendix 3) was represented as an individual node, linked to one of the five nodes representing capital asset types available prior to commercialization. Factors were grouped according to capital type, such that each factor was linked to a node representing only a single type of capital asset. To avoid unmanageably large CPTs, where necessary nodes representing factors were arranged in sub-groups such that the number of parent nodes per child node was limited to five (following Neil et al. 2000). The states defined for the factor nodes differed between factors, according to the scoring process outlined previously. In most cases, two Boolean states were defined, to indicate whether or not there was any evidence that a given factor had influenced a particular case.

The behaviour of any BBN depends on the conditional probabilities incorporated in the CPTs. These may be derived from a variety of sources, such as expert opinion or appropriate datasets. In the current example, probabilities were entered such that each factor had an equal influence on the state of the appropriate capital asset node to which it was linked. In this way, if all factors were in an appropriate (positive) state, then the probability associated with availability of the capital asset being 'high' would equal 1. Conversely, if all factors were in an alternative (negative) state, then the probability of availability of the capital asset being 'low' would equal 1. It is important to note that the factors were not otherwise weighted, and therefore the BBN is a form of 'null' model, assuming that all factors have an equal effect. However, the number of factors differed between different capital asset types (i.e. 14 in the case of natural capital, 10 for physical capital, five for social capital, 15 for human capital, and 22 for financial capital). As a result, any factor linked to financial capital will have had less individual influence on capital availability than (for example) factors linked to social capital assets, simply because of the difference in the number of factors grouped with these asset types.

In the case of the five nodes representing the change in availability of capital assets resulting from commercialization, CPTs were again constructed based on different combinations of the states of the parent nodes. For example, for the state of an asset node to be 'Large increase' with a probability of 1 , then the state of all parent nodes (representing asset availability prior to commercialization) would need to be 'High'. Conversely, if the state of all parent nodes were 'Low', then the state of the postcommercialization asset node would be 'Large decrease' with a probability of 1. Other combinations of 'High' and 'Low' states in the parent nodes were accorded intermediate probabilities in a way that was consistent across capital types. However, the CPTs were weighted in favour of the same capital type. A 
'High' state in the parent node of a particular asset type was given a slight positive weighting in the child node of the same asset type, such that 'High' availabilities of specific assets were reflected in a higher probability of an increase in these same assets post-commercialization. This weighting was applied in a consistent way across all five post-commercialization asset nodes, and was included to reflect the beliefs of the research team.

According to this model structure, the nodes representing availability of the different types of capital asset available prior to commercialization behave independently of each other. The probabilities associated with their different states ('high' or 'low') are determined by the states of the nodes representing factors to which they are individually linked. The behaviour of the nodes representing availability of capital assets post-commercialisation is more complex, but is dependent on the probabilities associated with the states of each of the pre-commercialisation asset nodes, inferred according to Bayes' theorem. In this case there is potential for interaction between the capital types, according to the values incorporated in the CPTs. 
Appendix 6. See attached spreadsheet - livelihood scores

Please click here to download file 'appendix6.xls'. 
APPENDIX 7. Exploration of model output.

Radar diagrams can be used to illustrate the variation between NTFP case studies in the availability of capital assets (Fig. A7.1), as inferred by the BBN from the factor scores for individual cases. The results highlight the pronounced differences that exist between NTFP case studies. For example, whereas Hongos (Cuajimoloyas) scored highly in terms of the availability of human and social capital, others (notably Copal, Pucasucho and Jipi Japa, El Carmen Surutú) scored much less well for these variables. In contrast, the case of Hongos (Cuajimoloyas) was characterized by relatively low availability of natural capital, in marked contrast to Cacao (San Silvestre) and Copal (Pucasucho). These diagrams illustrate the potential value of the $\mathrm{BBN}$ as a diagnostic tool for identifying the relative strengths and weaknesses of NTFPs proposed for commercialization in specific socio-economic situations, and providing a basis for identifying appropriate interventions to support commercialization efforts.

Fig. A7.1. Radar diagrams illustrating the contrasting availability in different asset types for commercialization of different NTFPs. Six NTFP case studies are presented, illustrating the range in outputs derived for the entire set of 19, namely: A, Hongos (Cuajimoloyas); B, Cacao (San Silvestre); C, Maguey (La Esperanza); D, Palma tepejilote (Yagavila); E, Copal (Pucasucho); F, Jipi Japa (El Carmen Surutú). The values presented are probabilities associated with the asset being of "high" availability, as inferred by the BBN when instantiated with the factor scores for the individual case studies. Abbrevations for capital asset types: N-natural; P-physical; S-social; H-human; F-financial. 
The model can also be used to make generalizations regarding the availability of the different capital assets required to support commercialization by combining the factor scores of all 19 case studies. Results indicate that for the NTFP case studies considered here, when considered together, the availability of human and physical assets was relatively high (with probabilities of availability being high of over 0.63 being recorded in both cases). In contrast, BBN inference indicated that natural and social capital were more likely to be classified as 'low' (with probabilities of 0.53 and 0.56 respectively) rather than 'high', suggesting that in general, these assets are more likely to constrain NTFP commercialization. Again, such analyses could potentially inform the planning of interventions designed to support communities in their development of NTFP resources.

The BBN can also be used to examine the potential impacts of commercialization on livelihoods, by referring to the nodes representing availability of assets post-commercialisation. Two examples are provided here to illustrate the range in responses obtained for the CEPFOR case studies (Figs. A7.2, A7.3), produced by instantiating the factor nodes of the network with the values for the individual case studies. In both cases, the impacts are represented as a probability distribution associated with the degree of change in the availability of different assets resulting from commercialization. In the case of Hongos (Cuajimoloyas), the most likely outcome is a small increase in all capital types. In contrast, in the case of Jipi Japa (El Carmen Surutú), the most likely outcome was no change in any of the capital asset types. The fact that outputs are represented as a probability distribution indicates how BBNs can be used to illustrate the uncertainty surrounding outcomes. For example, in the case of Jipi Japa (El Carmen Surutú), increases in the availability of all five assets could potentially occur as a result of commercialization, as indicated by probabilities greater than zero. However, the probability of assets declining in availability is greater than those of assets increasing in every case, suggesting that negative outcomes are more likely than positive outcomes in this particular case.

Fig. A7.2. The impacts of commercialization on availability of assets, as predicted by the BBN, for the case study of Hongos (Cuajimoloyas). These outputs were generated by instantiating the network with factor values for these individual case studies (see text).

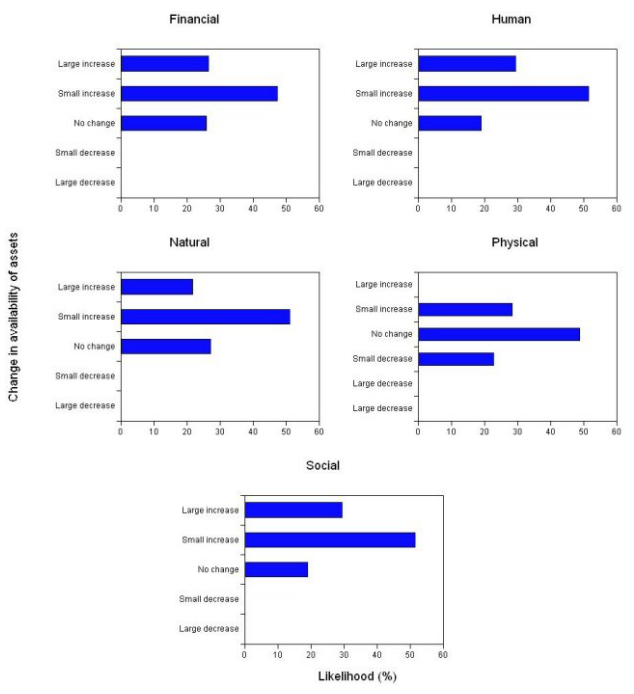


Fig. A7.3. The impacts of commercialization on availability of assets, as predicted by the BBN, for the case study of Jipi Japa (El Carmen Surutú). These outputs were generated by instantiating the network with factor values for these individual case studies (see text).

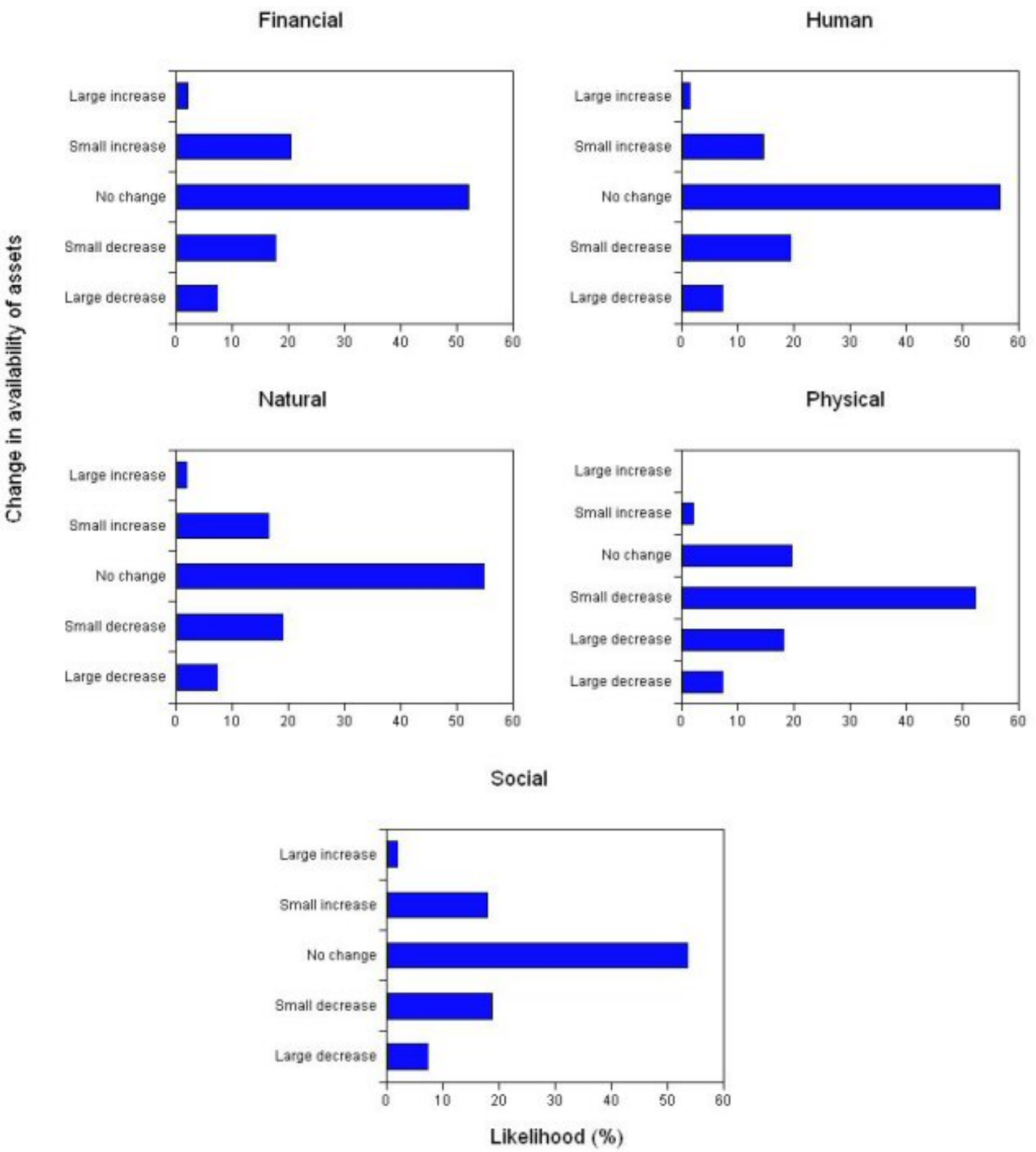




\section{Use of the BBN to explore policy options}

The BBN can also be used to evaluate the potential impact of different policy interventions on livelihoods. As an illustration, three different interventions are considered here: (1) provision of credit for community level NTFP-based enterprises, (2) improvements to rural transport and communication infrastructure, and (3) promotion of better management of the communal natural resource, for example through the provision of incentives. To explore these potential policy impacts, three case studies were chosen to represent the range of values encountered in the CEPFOR case studies, with respect to the availability of capital assets: Hongos (Cuajimoloyas), Maguey (La Esperanza) and Jipi Japa (El Carmen Surutú). Policy specialists within the research team then defined the likely impact of the interventions on the state of 66 factors identified in the research as influencing the commercialization process, based on expert judgement. Each of the interventions was adjudged to affect a suite of different factors. The number of factors affected was different between the three interventions, being 22, 16 and 16 respectively. Details of the potential impact of the interventions on the factors are described on an appended spreadsheet (App. 4).

To determine the potential impact of these interventions on livelihoods, the BBN case file for each of the three products was amended by changing the state of factors adjudged to be affected by the intervention, and by instantiating the nodes appropriately. The predicted effects of the intervention on the availability of assets required to support livelihoods, according to the DFID livelihood framework, was then illustrated using radar diagrams (Fig. A4). The results illustrate how the impacts of particular policy interventions are likely to differ among NTFP case studies, reflecting their different asset availabilities and the state of the factors prior to the intervention. Impacts were generally more pronounced for Jipi Japa (El Carmen Surutú) than for the other case studies considered, reflecting the relatively low availability of capital assets at the outset in this case study (Fig. A4). Interventions also differ in terms of the capital that they most affect. For example while Intervention 1 generally increased financial capital assets, it had little effect on natural capital. In contrast, Intervention 3 had a pronounced impact on availability of natural capital (Fig. A7.4).

These results highlight the value of the $\mathrm{BBN}$ as a decision support tool, enabling the potential impact of different policy interventions to be evaluated. The results suggest that it might be difficult to generalize among NTFPs regarding the potential impact of an intervention. Effective interventions depend upon understanding the factors limiting NTFP commercialization in each specific case, as represented here by the factor scores. Where availability of assets is relatively high, such as human and social capital in the case of Hongos (Cuajimoloyas), the impacts of any intervention on these assets are likely to be relatively slight. However, in cases where assets are lacking, policy interventions can be highly effective in increasing the availability of assets on which livelihoods depend, and therefore in increasing the probability of NTFP commercialization being successful. The relationship between policy interventions and the BBN is illustrated by an expanded analytical framework (Fig. A7.5). 
Fig. A7.4. Radar diagrams illustrating the predicted impacts of different policy interventions on the availability of different asset types for commercialization of different NTFPs. Three NTFP case studies are presented, illustrating the range in outputs derived for the entire set of 19, namely: A-Hongos (Cuajimoloyas); B-Maguey (La Esperanza); C-Jipi Japa (El Carmen Surutú). The values presented are probabilities associated with the asset being of "high" availability, as inferred by the BBN when instantiated using data for the individual case studies. Abbrevations for capital asset types: N-natural; P-physical; S-social; H-human; F-financial. The first column presents values for the NTFP case studies as determined by the CEPFOR research, representing the current situation. The three subsequent columns illustrate predictions according to three policy interventions, respectively: (1) provide credit for community-level NTFP-based enterprises, (2) improve rural transport and communication infrastructure, and (3) promote better management of the communal natural resource.
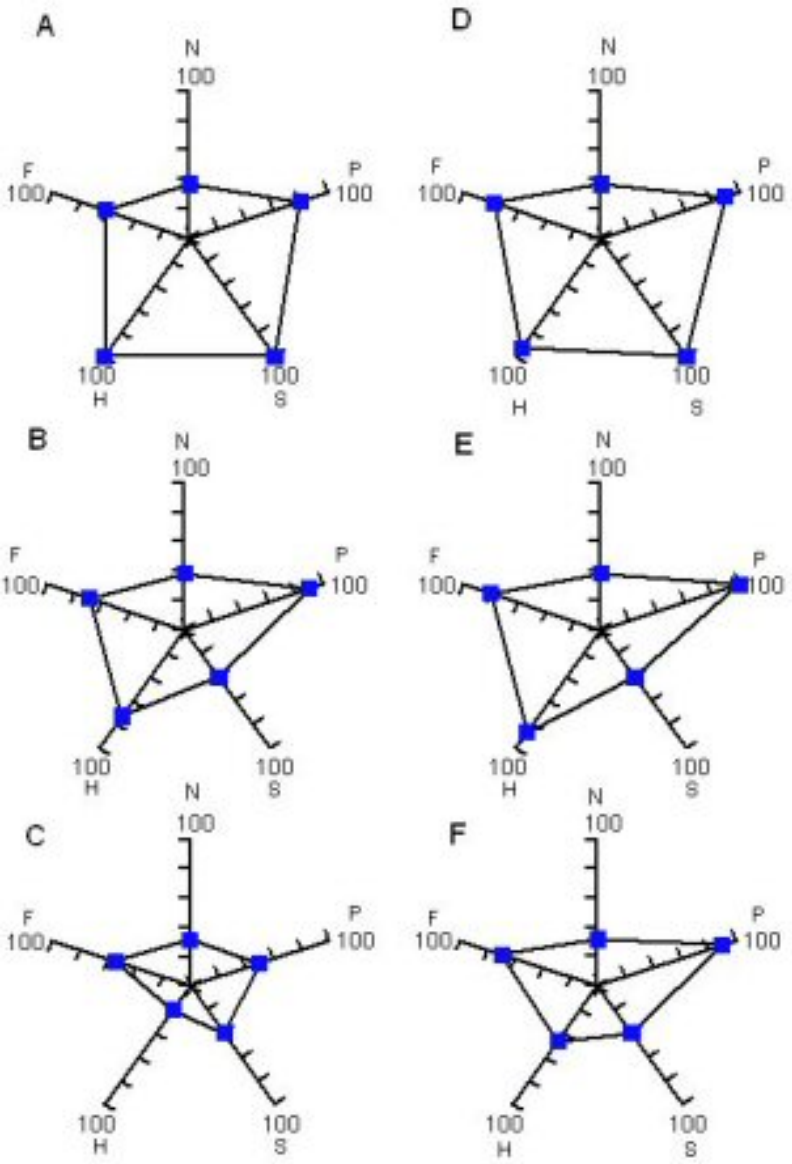
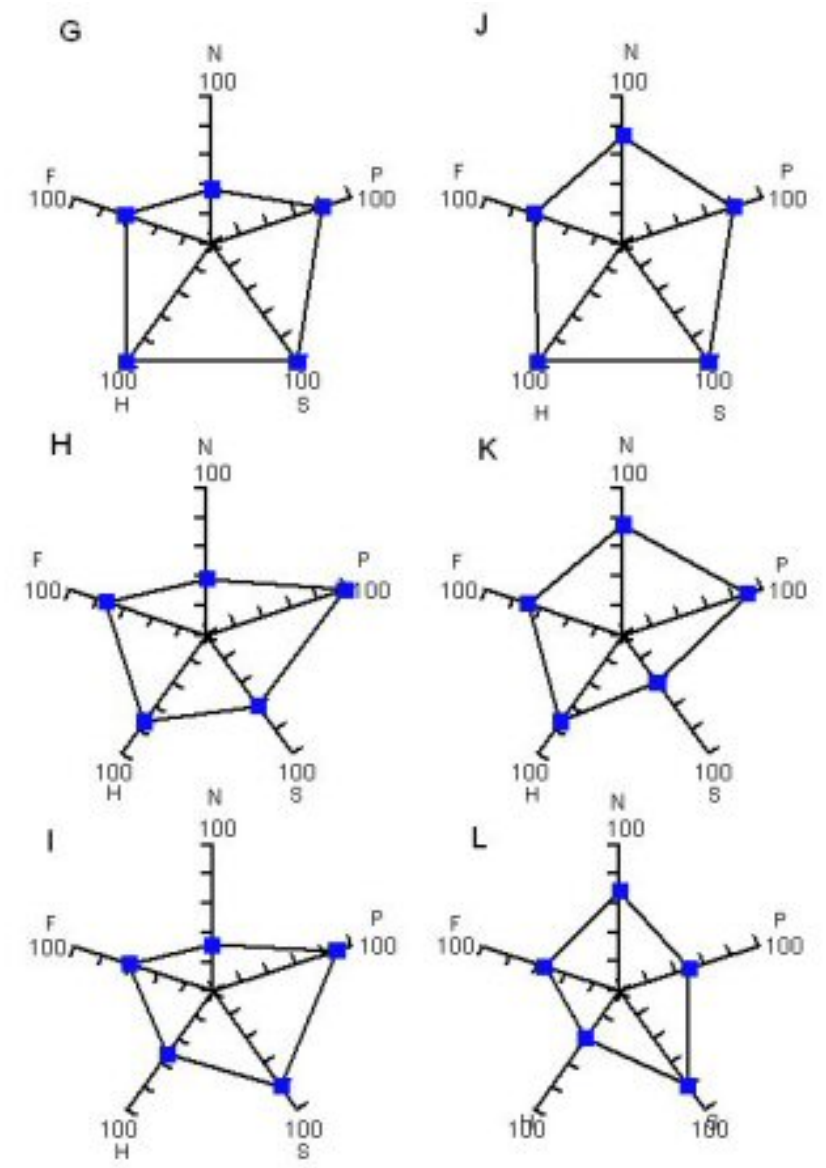
Fig. A7.5. Expanded analytical framework for assessing the impact of policy interventions on NTFP commercialization processes and on livelihoods. We propose that policy interventions mediated through appropriate institutions and processes will influence both the factors influencing commercialization and the process of NTFP commercialization itself, as well as alternative livelihood strategies. Policy context will also influence the vulnerability context of actors involved in commercialization, reflecting the impact of external shocks, market trends, seasonal variation, etc. The impact of policy interventions on livelihoods is determined by their impact on availability of the five types of asset before and after commercialization.

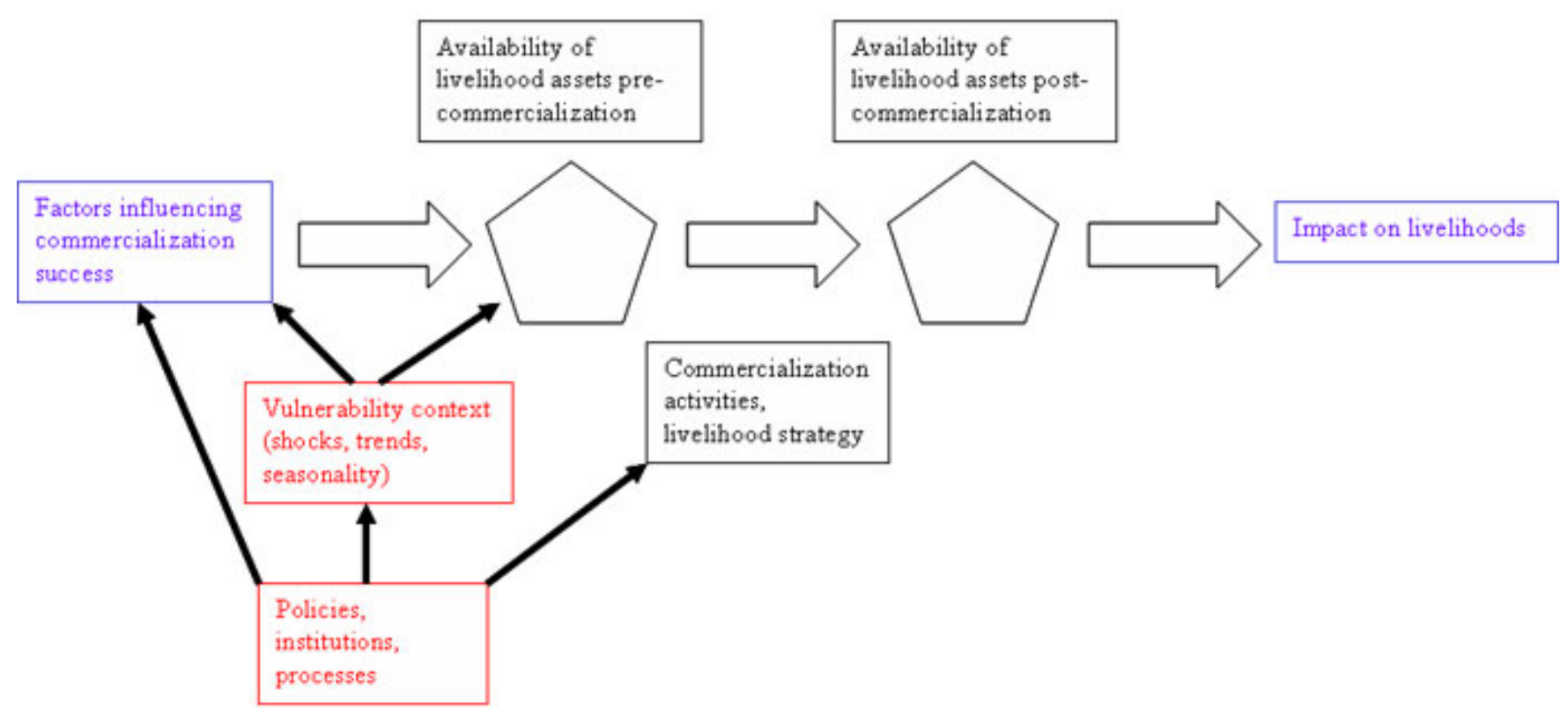


APPENDIX 8. Development of a decision-support tool.

One of the main applications of a BBN is the development of tools to support decision-making. In this case, an additional set of nodes was added to the network to enable impacts on livelihoods at both household and community levels to be predicted. Two nodes, respectively representing household- and community-level impacts, were linked to each of the nodes representing the change in availability of assets as a result of commercialization. Each was assigned five possible states signifying the impact on livelihoods, respectively labelled 'Very negative', 'Negative', 'Neutral', 'Positive' and 'Very positive'. The CPTs for these nodes were adjusted so that the outputs of these nodes precisely mirrored the probability distributions of the CIFOR impact scores, when the factor nodes were instantiated with the probability distributions for all NTFP cases combined.

An interactive decision-support tool was developed using this version of the BBN, incorporating default factor scores for the 19 NTFP case studies combined, by construction of an interface in Java. This tool (the 'CEPFOR Decision Support Tool', CDST) has been made freely available (as a downloadable file; http://quin.unep-wcmc.org/forest/ntfp/outputs.cfm). The CDST enables predictions to be made regarding the impact of commercialization on livelihoods, by entering factor scores for the NTFP in question. The CDST also exploits one of the advantages of BBNs, by allowing impacts to be inferred even where information is lacking on particular factors. Furthermore, if information about a particular factor is uncertain, then this can be entered into the network by instantiating the relevant factor node with a probability value of less than 1 . 